\title{
Gene transfer of human CD40Ig does not prevent rejection in a non-human primate kidney allotransplantation model
}

\author{
Mathieu Angin a, Nicolas Poirier a , Nahzli Dilek a, Caroline Le Guiner ${ }^{\mathrm{b}}$, Alice Toromanoff b, \\ Antoine Blancher ${ }^{c}$, Yan Cherel ${ }^{\mathrm{d}}$, Jack-Yves Deschamps ${ }^{\mathrm{d}}$, Xavier Tillou ${ }^{\mathrm{a}}$, Karine Renaudin ${ }^{\mathrm{e}}$, David Minault ${ }^{\mathrm{a}}$, \\ Jeremy Hervouet ${ }^{\mathrm{a}}$, Gilles Blancho a, Bernard Vanhove ${ }^{\mathrm{a}}$, Ignacio Anegon ${ }^{\mathrm{a}}$, Brigitte Le Mauff ${ }^{\mathrm{a}, \mathrm{f}, *}$ \\ a INSERM UMR 1064-Center for Research in Transplantation and Immunology, CHU de Nantes, IUN, Nantes, Université de Nantes, Nantes, France \\ b INSERM 1089, IRT UN, Université de Nantes, Faculté de Médecine, Nantes, France \\ ' Laboratoire d'Immunogénétique Moléculaire, EA 3034, Faculté de Médecine Purpan, Université Paul Sabatier, Toulouse 3, Toulouse, France \\ d INRA UMR 703, Ecole Nationale Vétérinaire, Nantes, France \\ e Centre Hospitalier Universitaire Hôtel Dieu, Service d'Anatomie Pathologique, Nantes, France \\ ${ }^{\mathrm{f}} \mathrm{CHU}$ de Caen, Laboratoire d'Immunologie et Immunopathologie, Caen, F-14000, France
}

\section{A R T I C L E I N F O}

\section{Article history:}

Received 7 August 2012

Received in revised form 12 October 2012

Accepted 16 October 2012

\section{Keywords:}

Transplantation

Tolerance

Primate

Costimulation

CD40/CD40L

\begin{abstract}
A B S T R A C T
Background: Blockade of costimulation signaling required for immune response, such as CD40/CD40L and $\mathrm{CD} 28 / \mathrm{B} 7$, is a reasonable strategy to prevent rejection and in defined combinations may allow donor specific tolerance. Indeed, in rodents, costimulation blockade with CD28/B7 antagonists or with CD40Ig was able to induce regulatory $\mathrm{T}$ cells and transplant tolerance whereas in primates, anti-CD40 antibodies, anti-CD40L antibodies or CTLA4Ig, used as monotherapy, significantly delayed graft rejection.

Methods: Using an adeno-associated virus (AAV) vector mediated gene transfer of a human CD40Ig fusion protein (hCD40Ig) in primates, we evaluated the capacity of this costimulation blockade molecule interfering with CD40/CD40L signaling in prolonging kidney transplants in cynomolgus monkeys.

Results: This gene transfer strategy allowed for maintaining a plateau of hCD40Ig production within two months and avoided a high-scale production phase of this molecule. Although the hCD40Ig was able to bind efficiently to human and macaque CD40L and high $(>200 \mu \mathrm{g} / \mathrm{ml})$ transgene expression was obtained, no effect on graft survival was observed. In addition, there was no inhibition of humoral response to vaccination. In vitro, hCD40Ig strongly increased mixed lymphocyte reaction, and when compared to the anti-CD40L antibody h5C8, was not as potent to induce complement-dependent cytotoxicity.

Conclusion: These data suggest that CD40/CD40L blockade using a non-depleting CD40Ig fusion protein, a therapeutic strategy that showed efficacy in rodents, is not able to modulate the immune response in primates. These data highlight important biological differences between rodent and primate models to evaluate therapeutic strategies at the preclinical level.
\end{abstract}

(c) 2012 Elsevier B.V. All rights reserved.

\section{Introduction}

Several bioreagents are being developed to specifically target the molecular interactions involved in cellular activation leading to graft rejection. Costimulation of lymphocytes is a critical step since TCR stimulation in the absence of costimulation has been shown to induce cell anergy in vitro. This was achieved using the fusion molecule CTLA4Ig, an inhibitor of CD28/B7 interactions able to induce a potent immunosuppression [1,2]. However, the tolerogenic effect of CTLA4Ig is more difficult to obtain in vivo and seems restricted to certain animal models or requires associations with other reagents $[3,4]$.

\footnotetext{
* Corresponding author at: CHU, Laboratoire d'Immunologie et Immunopathologie, av Clemenceau, 14033, Caen, France. Tel.: + 33231272551.

E-mail address: lemauff-b@chu-caen.fr (B. Le Mauff).
}

Interactions between CD40L (CD154) expressed by activated T-cells and CD40 expressed by antigen presenting cells (APCs) constitute an upstream step in costimulation signaling. It induces an upregulation on APCs of costimulatory molecules such as B7-1 (CD80), B7-2 (CD86), ICAM-1 (CD54), LFA-3 (CD58) and cytokines [5,6]. The CD40L/CD40 interaction also triggers the proliferation and differentiation of $\mathrm{B}$ cells into memory cells as well as isotype switch [7]. CD40 ligand is also expressed on activated platelets [8], endothelial cells [9] and other cells. In addition, CD40, expressed on T lymphocytes, may also play a direct costimulatory role during $\mathrm{T}$ cell activation [10]. Given the major role of CD40/CD40L interactions in immune response, tremendous efforts have been made in blocking this pathway to prevent allograft rejection in experimental models [11]. Blocking anti-CD40L monoclonal antibodies (Mab) delay rejection in several models, including primates, even when given as a monotherapy [12-17]. Nevertheless, long-term skin graft survival in rodents can only be achieved through association 
with donor cells [18] and in primates with donor cells and rapamycin [19]. Moreover, unexpected thrombotic effects using anti-CD40L in clinical trials curbed the development of the antibody approach [20].

\section{Objective}

Our laboratory has developed a rodent gene transfer model using adenovirus producing a CD40Ig fusion molecule that prevents rejection in more than $90 \%$ of heart-grafted rats [21,22]. The animals with long-term graft survival developed regulatory $\mathrm{T}$ cells which, when transferred to naive animals allowed graft of the same donor strain to be accepted without further treatment. These cells have been characterized as $\mathrm{CD}^{+}{ }^{\mathrm{CD}} 45 \mathrm{RC}^{\text {low }} \mathrm{T}$ cells $[22]$. To evaluate the efficacy of the CD40Ig molecule in primates we selected a gene transfer strategy using AAV vector injection into skeletal muscle, which allowed high transgene expression for several months [23,24].

This study is not meant to be a pre-clinical gene therapy model but is designed to validate the relevance of hCD40Ig while avoiding the steps of production of large quantity of protein for non-human primate model. Our main objective was to assess for the first time the tolerogenic effect of hCD40Ig in a non-human primate transplantation model. The in vitro properties of hCD40Ig were compared to that of anti-CD40L antibodies known for their in vivo efficacy.

\section{Material and methods}

\section{1. hCD40Ig cloning and protein testing}

The extracellular portion of human CD40 was cloned in a plasmid containing the leader peptide from oncostatin $\mathrm{M}$ and the $\mathrm{Fc}$ fragment of human IgG1. Human CD40Ig (hCD40Ig) was cloned in a pZA plasmid vector containing the RSV promoter, upstream of WPRE with the ITR of AAV2. Recombinant AAV serotype 1 and 8 vectors were produced by the Vector Core at the University Hospital of Nantes, France, as previously described [23]. A clone producing hCD40Ig was obtained by transfecting the hCD40Ig/AAV plasmid and the resistance gene to neomycin in 293sz cells using lipofectamine (Life Technologies, Saint Aubin, France). hCD40Ig protein was purified from supernatant by protein A affinity chromatography.

\section{2. hCD40Ig ELISA}

Plates were coated with mouse anti-human CD40 (clone mAb89, Immunotech, Marseille, France). A goat anti-human CD40 (R\&D systems, Lille, France) was used followed by a biotinylated anti-goat IgG (Jackson ImmunoResearch, Suffolk, UK). Peroxydase linked streptavidin was applied and reaction revealed using ABTS (2,2'-azino-bis(3ethylbenzthiazoline-6-sulphonic acid)) (Sigma Aldrich, L'Isle D'Abeau Chesne, France) and analyzed by spectrophotometry. Purified human CD40Ig (Alexis, Farmingdale, NY) was used as standard.

\section{3. $h C D 40 I g$ in vitro functional tests}

Binding of hCD40Ig was evaluated on human and primate PBMC isolated from human and primate using Ficoll gradient centrifugation and activated with PMA/ionomycin, incubated with purified hCD40Ig followed by an anti-human IgG-FITC (Jackson ImmunoResearch) and analyzed on a FacsCalibur (BD Biosciences, Le Pont de Claix, France).

CD40L-proliferation dependent B cells were co-cultured with mitomycin-treated CD40L-expressing fibroblasts (gift from F. Briere, Schering-Plough, Dardilly, France) in presence of IL-2 $(50 \mathrm{U} / \mathrm{ml})$ and IL-10 (50 ng/ml) with or without purified hCD40Ig and pulsed during the last $16 \mathrm{~h}$ with $\mathrm{H} 3$-thymidine $(1 \mu \mathrm{Ci} /$ well $)$.

\subsection{Animals}

3-5 kg male captive-bred cynomolgus macaques (Macacus fascicularis) were purchased from BioPrim (Baziège, France) and selected based on the absence of neutralizing antibody against AAV serotypes 1 or 8 (i.e. about $15 \%$ of the tested animals). The protocol was approved by the local committee for animal experimentation (Comité d'éthique en expérimentation animale des Pays de la Loire, France).

\section{5. $A A V / h C D 40 I g$ injection}

Animals were anesthetized using Ketamine (10 mg/kg). Recombinant AAV was injected through retrograde perfusion in the great saphenous vein at $3.510^{12} \mathrm{vg} / \mathrm{kg}$ and infused under pressure $(300 \mathrm{~mm} \mathrm{Hg})$ using a tourniquet $[23,24]$. Immunization against vector and transgene was avoided using Cellcept ( $40 \mathrm{mg} / \mathrm{kg} /$ day) (Roche) and prednisolone (5 mg/day) (Sanofi-Aventis) during 2-3 weeks.

\subsection{Graft}

Procedures were carried out as previously described [25]. Briefly, animals were put under general anesthesia using Zoletil (Virbac, Carron, France) and ventilation with a mixture of $60 \%$ nitrous oxide, $40 \%$ oxygen, and 3\% Isoflurane (Forène; Abbott). MHC typing was performed using PCR-SSO targeted on exon 2 [26]. Amongst the tested animals, $8 \%$ were ABO compatible, fully DR-MHC mismatched and selected as donors. Transplantation was performed after bilateral nephrectomy.

\subsection{Vaccination}

Animals received tetanus vaccine (Pasteur, Paris, France) three weeks before AAV injection as well as a booster shot a few days prior AAV injection. Then, before transplantation, they received an injection of a combined vaccine against tetanus and diphtheria (Revaxis).

\subsection{Histological analysis}

Biopsies were collected at time of rejection for conventional histological examination using hematoxilin/eosin and May-Grunwald-Giemsa staining. Samples were snap-frozen in Tissue-Tek (Sakura Finetek, Villeneuve d'Ascq, France). Frozen sections were air dried before acetone fixation, saturated and incubated with primary antibodies, followed by fluorescent secondary antibodies. Primary antibodies were rabbit anti-human CD3 (DAKO, Trappes, France), mouse anti-human CD4 (4B12, DAKO), human anti-CD8 (B9.11, Beckman Coulter, Villepinte, France), human anti-CD11b (BEAR1; Beckman Coulter) and human anti-CD20 (L26; DAKO). The sections were examined by standard fluorescence microscopy (Carl Zeiss, Le Pecq, France).

\subsection{Anti-tetanus and anti-diphtheria ELISA}

Plates were coated with tetanus toxoid (Aventis, Paris, France) or diphtheria toxoid (Pasteur) respectively. An alkaline-phosphatase linked anti-human immunoglobulin was used (Caltag, Buckingham, UK) followed by $p$-Nitrophenyl Phosphate (BioTek, Colmar, France) and analyzed by spectrophotometry.

Anti-donor alloantibodies were evaluated on frozen donor splenocytes incubated with heat inactivated recipient sera as previously described [27], incubated with FITC-labeled goat anti-monkey IgG (H\&L, AbD Serotec, Düsseldorf, Germany) or rabbit anti-human IgM (AbD Serotec) and analyzed on a LSR II flow-cytometer (Becton Dickinson).

\subsection{Complement-mediated cytotoxicity assay}

CD40L-transfected fibroblasts were incubated with h5C8 antibody (anti-CD40L; Biogen IDEC, Nanterre, France) or hCD40Ig, followed by 
incubation with rabbit complement (Sigma-Aldrich). Cells were stained with propidium iodide (Sigma-Aldrich) and analyzed on a LSR II. Specific cytotoxicity was calculated as the percentage of propidium iodide-positive cells as previously described [25] and using unmodified fibroblasts as controls.

\subsection{Mixed lymphocyte reaction (MLR)}

Freshly isolated PBMC were co-cultured with allogeneic irradiated PBMC and dilutions of h5C8 or hCD40Ig for 5 days at $37{ }^{\circ} \mathrm{C}, 5 \% \mathrm{CO}$, in complete medium (RPMI 1640, 10\% heat-inactivated pooled sera, $2 \mathrm{mM}$ L-glutamine, $100 \mathrm{U} / \mathrm{ml}$ penicillin, $0.1 \mathrm{mg} / \mathrm{ml}$ streptomycin, $1 \%$ nonessential amino acids, $1 \mathrm{mM}$ sodium pyruvate and $5 \mathrm{mM}$ Hepes, all from Sigma). Cells are pulsed with $1 \mu \mathrm{Ci}$ of $3 \mathrm{H}$-thymidine during the final 8 h of culture, harvested and counted by a scintillation counter (Topcount, Packard).

\subsection{Flow-cytometry staining}

PBMC were isolated from fresh blood by density centrifugation. To evaluate $\mathrm{T}$ cell activation, PBMC were labeled with $\mathrm{CD} 3-\mathrm{PeCy} 7$ and CD62L-PE (FMC46, AbD Serotec, Oxford, UK), or CD69-PE (FN50, BD Biosciences), LAG-3-biotin (11E3, provided by Dr. F. Triebel, ChâtenayMalabry, France) and streptavidin-PE, or CD25-FITC (M-A251, BD Biosciences). All antibodies used were previously checked for cross-reactivity on cynomolgus cells. Data were acquired on a LSR II flow cytometer (BD Biosciences).

\section{Results}

4.1. hCD40Ig construction and interactions with non-human primate cells

We have previously used murine CD40Ig in a rat gene transfer and transplantation model [22]. For assessing efficacy in a preclinical primate model (cynomolgus), the sequence encoding a extracellular portion of human CD40 and the Fc portion of human IgG1, CD40Ig fusion protein, was used to generate AAV vectors (AAV/hCD40Ig). After transduction of 293 cells using AAV/hCD40Ig, hCD40Ig was purified from the supernatant to test the in vitro properties of the molecule.

The ability of hCD40Ig to bind to human and cynomolgus peripheral blood mononuclear cells (PBMC) was tested in vitro (Fig. 1a). hCD40Ig dose-dependently bound to activated PBMC with a comparable efficacy in both species.

The biological activity of hCD40Ig was evaluated on B cell proliferation which is CD40L-dependent [28]. Our data showed that hCD40Ig was able to dose-dependently and almost completely inhibit CD40L dependant B cell proliferation with a similar efficacy in human and cynomolgus (Fig. 1b).

\subsection{In vivo transduction efficiency}

Animals were injected with $3.510^{12} \mathrm{vg} / \mathrm{kg}$ AAV serotype 1 or 8 encoding hCD40Ig using the regional intravenous delivery route that is less immunogenic and allows higher transgene expression levels $[23,24]$. All animals expressed the hCD40Ig transgene at high levels peaking between 200 and $600 \mu \mathrm{g} / \mathrm{ml}$ in the plasma 30 to 60 days after gene transfer (Fig. 2). Circulating levels over $100 \mu \mathrm{g} / \mathrm{ml}$ were maintained several months after injection. One of the animals (OBCV5) exhibited a sudden drop of hCD40Ig levels 5 months after injection, suggesting a possible immunization against the fusion molecule. However, no anti-hCD40Ig antibodies were detected by ELISA (data not shown). Despite these high levels of circulating hCD40Ig, no side effect was noticed, including coagulation trouble, as has been observed using anti-CD40L antibodies in primate [20].

To test possible lymphocyte activation in vivo after AAV/hCD40Ig injection, severa activation markers were assayed by flow-cytometry (CD62L, CD69, CD25, LAG3) in the four injected animals. No significant differences were seen 30 days after AAV/hCD40Ig injection, or on the day of transplantation, as compared to pre-injection status (data not shown).

\subsection{Absence of efficacy of hCD40Ig on kidney graft survival}

Four animals were grafted post-injection with circulating hCD40Ig levels over $50 \mu \mathrm{g} / \mathrm{m}$ (Fig. 2). Among these animals two died three days after transplantation because of technical failure, with kidney biopsies showing a massive ischemic necrosis and/or acute tubulitis, with no major cell infiltrate detectable in necropsies. The two other animals rejected the grafts at day 7 post-transplantation (Fig. 3a), which is similar to untreated control animals, with a dense infiltrate of T cells in kidney biopsies (Fig. 3b). The only difference as compared to the infiltrate observed at day 6 in the two untreated control animals was a massive
A

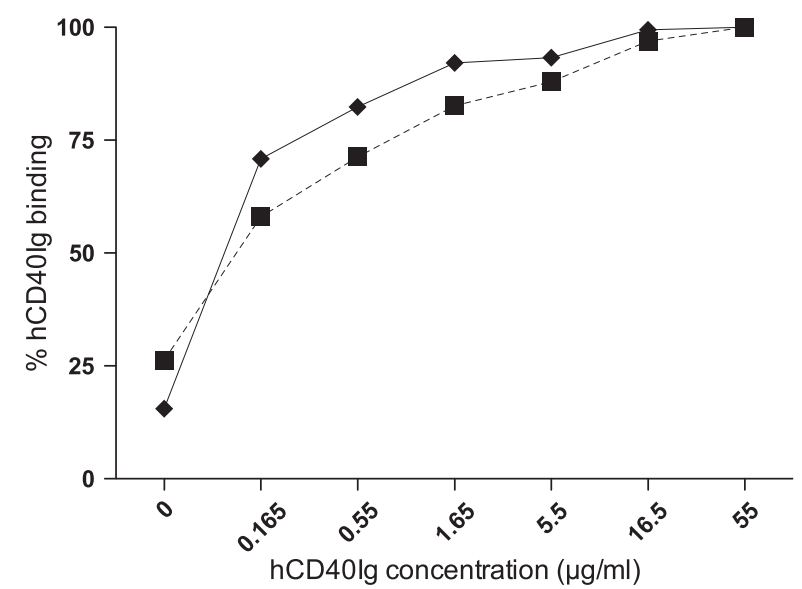

B

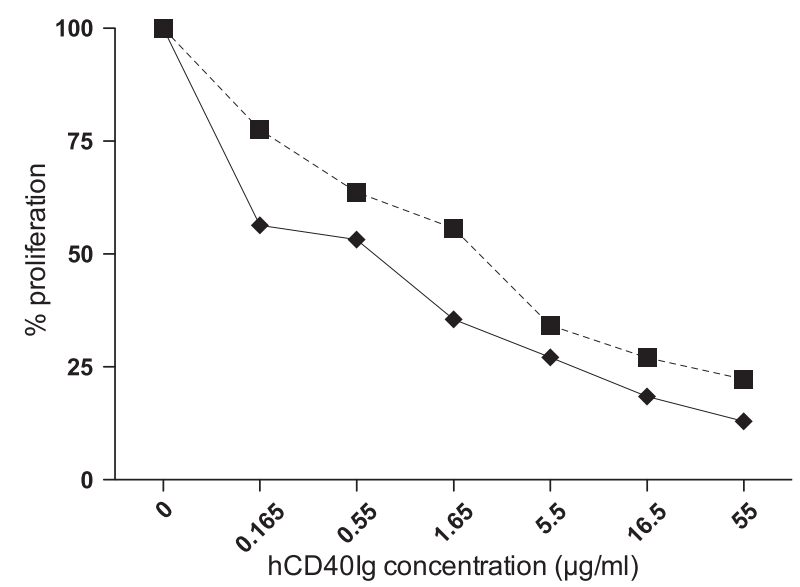

Fig. 1. A/ Binding of hCD40Ig to human and cynomolgus cells: PBMC from human (solid line) or cynomolgus (dotted line) activated by PMA/ionomycin, then incubated with hCD40Ig followed by anti-IgG FITC. The frequency of hCD40Ig-positive cells was measured by flow-cytometry. B/ Inhibiting properties of hCD40Ig: B cells from human (solid line) or cynomolgus (dotted line) blood were stimulated by CD40L expressing fibroblasts in the presence of IL2 and IL10, with or without hCD40Ig. The proliferation was determined by thymidine incorporation.

presence of $\mathrm{CD} 8^{+} \mathrm{T}$ cells (grade 5 vs. grade $2-3$ respectively) (Fig. 3c). No pro-thrombotic events were noticed after surgery.

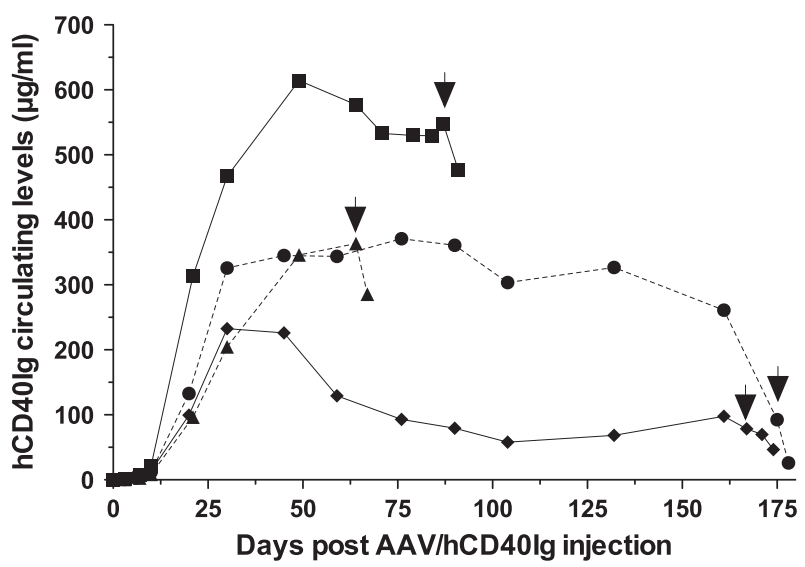

Fig. 2. hCD40Ig circulating levels in the four animals injected with $A A V / h C D 40 I g$ as assayed by ELISA. Black arrows represent the day of kidney grafting. Animals that had functioning grafts are figured with solid lines and those with technical failures in dotted lines. 


\subsection{Effect on humoral responses}

Before injection of AAV/hCD40Ig the animals were vaccinated with tetanus toxoid. Their ability to develop a secondary response was determined at time of transplantation after a booster vaccination. Animals receiving AAV/hCD40Ig were able to produce antibodies as efficiently as control animals after a secondary stimulation $(5.5 \pm 3.9 \mathrm{vs.} 7 \pm 1.6 \mathrm{IU} / \mathrm{ml}$ respectively, as compared to $0.1 \pm 0.1 \mathrm{IU} / \mathrm{ml}$ before vaccination). Primary response to diphtheria vaccination performed concomitantly at time of transplantation, while hCD40Ig was at high levels, was also normal although decreased vs. controls $(0.86 \pm 0.61$ in CD40Ig recipients vs. $2 \pm 1.1 \mathrm{IU} / \mathrm{ml}$ in controls as compared to $0.28 \pm 0.14 \mathrm{IU} / \mathrm{ml}$ before vaccination). Anti-donor antibodies were determined at time of rejection and were negative in all animals treated or not, which was probably related to the early timing of the test.

\subsection{Comparison of hCD40Ig and anti-CD40L antibody}

Owing to the differences observed with hCD40Ig as compared to the described effects of several anti-CD40L antibodies, we analyzed further some biological properties of our fusion protein with reference to a humanized anti-CD40L antibody (h5C8).

First, we compared the ability of the two molecules to inhibit an allogeneic stimulation in vitro. The anti-CD40L antibody was not able to inhibit cell proliferation and even induced a peak of cell proliferation in both human and cynomolgus (Fig. 4a). Surprisingly, hCD40Ig induced an even stronger activating effect, leading to a 6-fold increase in thymidine incorporation as compared to control.

Another possible mechanism of action of Mab is their depleting effect mediated by Fc dependent interactions. A cytotoxic assay was performed on CD40L-transfected fibroblasts. h5C8 was able to lyse CD40L positive cells at low concentrations $(1.25 \mu \mathrm{g} / \mathrm{ml})$ (Fig. 4b). hCD40Ig was also able to kill cells but only to a limited extent (20\% compared to $55 \%$ for h5C 8$)$ and at high concentrations $(10 \mu \mathrm{g} / \mathrm{ml})$.

\section{Discussion}

Interference with CD40/CD40L costimulation signaling have shown potential efficacy in transplantation models, including non-human primates [11]. However, an unexpected side-effect in pre-clinical trials, thromboembolism, has been observed with anti-CD40L Mab resulting in interruption of these protocols [20]. Anti-CD40 Mabs have also emerged as an alternate solution and allowed prevention of rejection $(12,28)$. In addition to Mab, a CD40Ig fusion protein is able to prevent rejection in several rat models $[21,22,29]$ and we consequently considered adapting this strategy in primates. We used AAV vectors to obtain stable circulating levels prior to transplantation, as previously done using AAV encoding for CTLA4Ig [23,24]. Indeed, all animals receiving AAV/hCD40Ig injection had rapid and long-standing production of the transgene, allowing transplantation with high levels of circulating hCD40Ig. Nevertheless, kidney grafts were rejected within seven days, which is similar to control untreated recipient animals. These results were quite underwhelming when compared to primate transplantation models using either anti-CD40L [15,30-34] or anti-CD40 Mab in monotherapy $(12,17,35)$, although some of them were only observed in association with Sirolimus and donor specific transfusion [19]. Most of these studies used rhesus monkeys models [33-35] when there is an overall trend to shorter graft survival in cynomolgus as compared with rhesus, even with prolonged treatment.

A

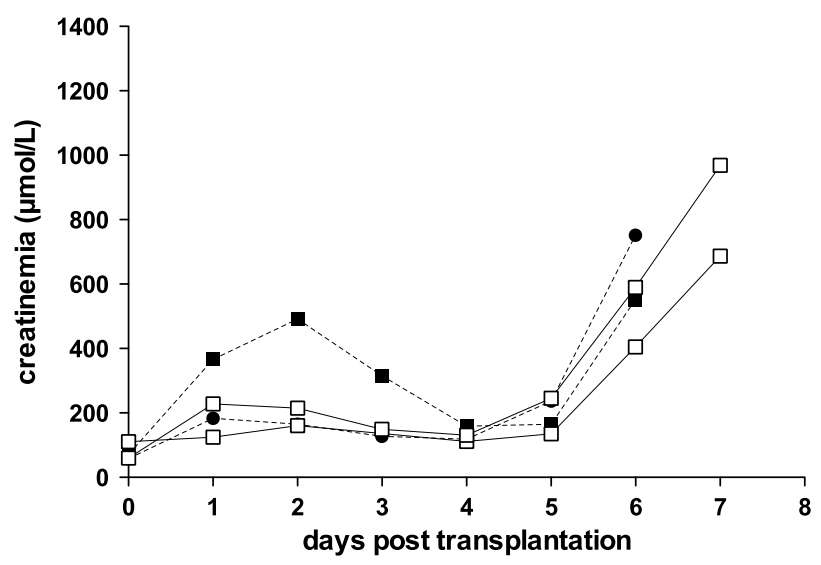

B

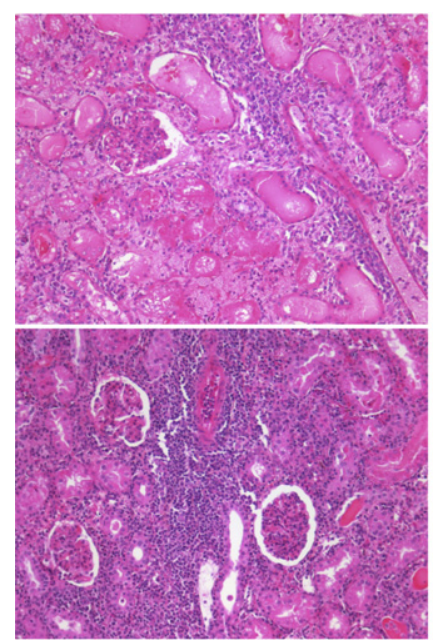

C
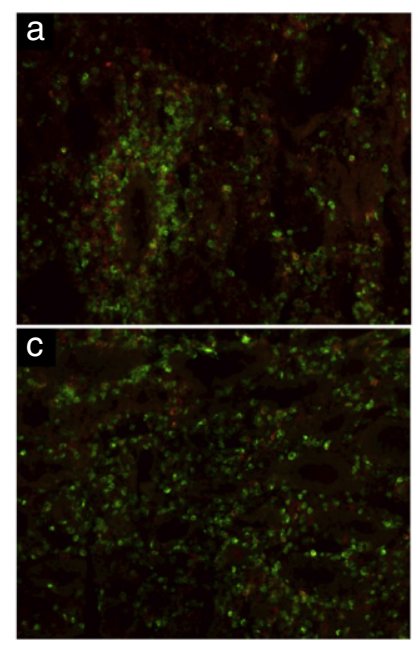

b
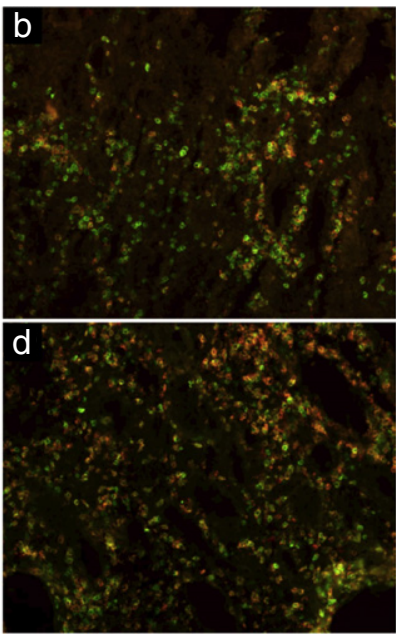

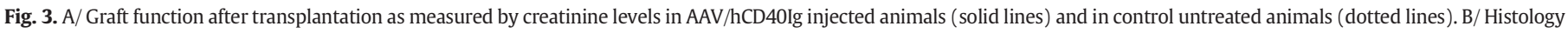

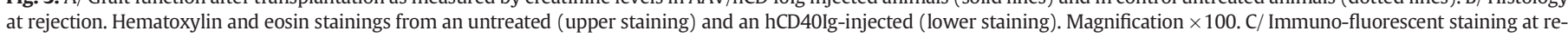
jection. Snap frozen graft biopsies were stained CD4 (a,c) or CD8 (b,d) from untreated, d7 (a-b), or hCD40Ig, d6 (c-d) animals. Magnification $\times 20$. 
A
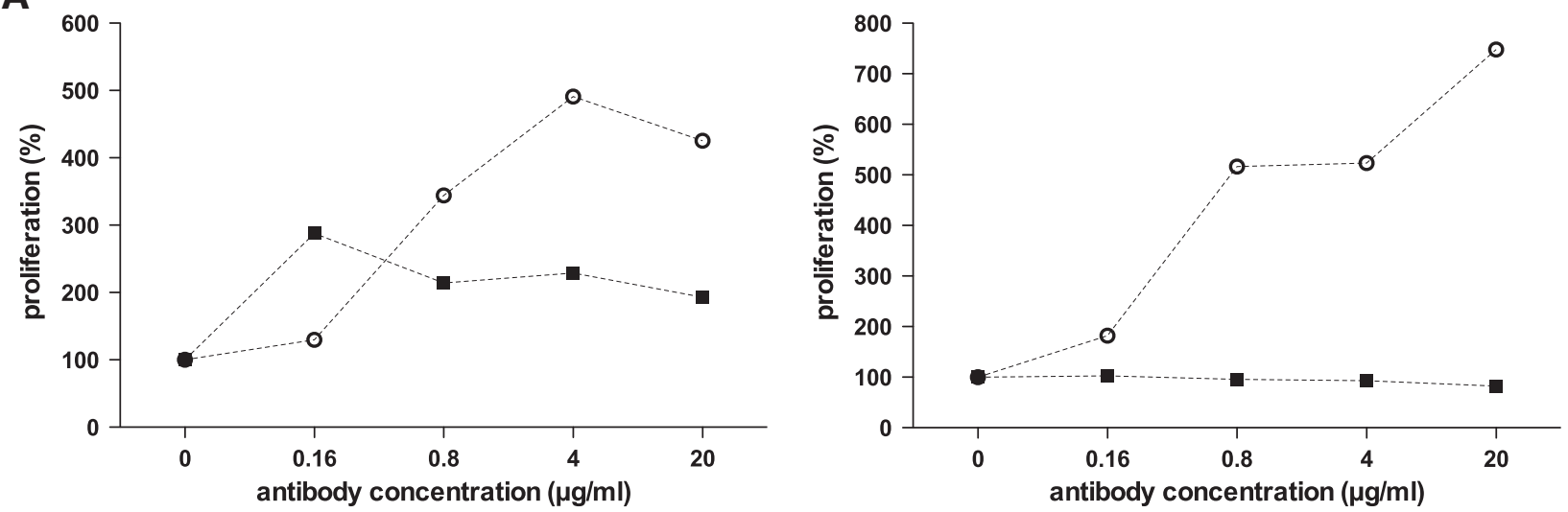

B

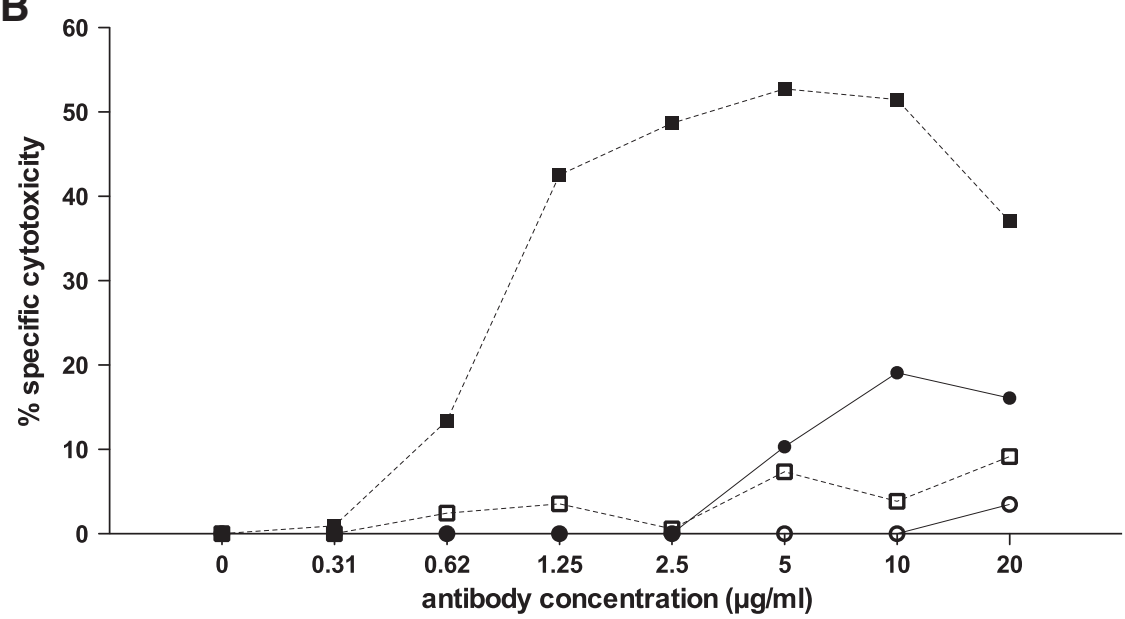

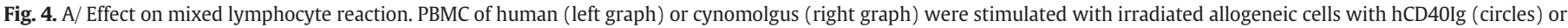

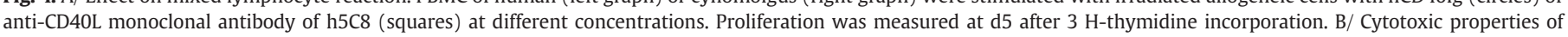


with propidium iodide and analyzed by flow-cytometry.

Kidney rejection in our model was associated with a dense T cell infiltrate, mostly constituted by $\mathrm{CD} 8^{+} \mathrm{T}$ cells. This is in agreement with observations of anti-CD40 MAb treatment, using either 4D11 [34] or Chi220 [3] antibodies. This suggests that $\mathrm{CD}^{+}{ }^{+} \mathrm{T}$ cells are more resistant to $\mathrm{CD} 40$ / CD40L blockade. Indeed, CD40L has been shown to be mostly expressed on allogeneic-activated $\mathrm{CD} 4^{+}$and not $\mathrm{CD}^{+}{ }^{+} \mathrm{T}$ cells [36]. On the other side, $\mathrm{CD}^{+} \mathrm{T}$ cell differentiation is dependent on $\mathrm{CD}^{+} \mathrm{T}$ cell help, which in the so-called licensing model is CD40/CD40L dependent. There are some options for $\mathrm{CD} 40$ autonomy of $\mathrm{CD}^{+} \mathrm{T}$ cell responses since virus-induced CTL can differentiate in CD40L knocked-out mice [37]. In addition several transplantation models have shown that $\mathrm{CD} 8^{+} \mathrm{T}$ cell mediated rejection was CD40/CD40L blockade resistant $(39,40)$ and CD4-dependent CTL can switch to CD4-independent response if the frequency of precursor is high enough $[38,39]$. In addition, memory T cells are resistant to $\mathrm{CD} 28$ or $\mathrm{CD} 40$ dependant costimulation blockade, resulting in $\mathrm{CD} 40 / \mathrm{CD} 40 \mathrm{~L}$ blockade failing to induce tolerance after priming $[40,41]$. Considering that infections can generate alloreactive memory $\mathrm{T}$ cells through cross reactive cells [42], it is possible that such resistant cells might be present in capture-bred primates, induced by exposure to infections. We cannot exclude that part of these $\mathrm{CD}^{+}$infiltrating $\mathrm{T}$ cells are $\mathrm{CD} 8^{+}$Tregs identified in the rat model of allotransplantation [22] that cannot block predominant graft rejecting mechanisms.

The allogeneic response can also have a humoral counterpart with anti-donor antibodies. Here, such antibodies were not detected probably because animals were euthanized before their appearance. Blocking CD40-CD40L interactions could have an impact on the humoral response [15]. When analyzing the responses to vaccine as protein antigens, we did not detect significant differences in responses to diphteria or tetanus toxoid, used to detect primary or secondary response respectively.

The comparison of our results to other primate observations using anti-CD40L suggests that despite targeting the same molecule, the two strategies might involve different mechanisms. The first possible mechanism of in vivo action of Mabs is the inhibition of the ligand/receptor interaction that might not be properly estimated in vitro. In rat, CD40Ig in vitro is able to inhibit the proliferation of $\mathrm{CD}^{+} \mathrm{CD}^{+} 5^{-} \mathrm{T}$ cells to allogeneic stimulation [22]. Reports on anti-CD40L effects on T cell proliferation, including h5C8, indicate partial inhibition $[30,43]$. In our hands, when added to human or primate mixed lymphocyte reaction both h5C8 and hCD40Ig boosted cell proliferation, the latter even more strongly. Such activation had already been noticed with h5C8 $[43,44]$. In our case, the hCD40Ig may have achieved a high level of cross linking in vitro, in a similar fashion to immobilized anti-CD40L $[43,44]$, and this may have resulted in a strong signaling through CD40L expressed by the $\mathrm{T}$ cell and a stronger activation in the MLR setting. In vivo, no noticeable increase in activation markers was seen on PBMC after hCD40Ig expression. More surprising is the difference of in vitro effect of hCD40Ig between the rat model where there was inhibition [22] and the primate model where there was activation. None of these results are comparable to those observed in mice with a similar construct that had no effect on $\mathrm{T}$ cell proliferation $[45,46]$. Nevertheless our construct was functional, as it was clearly able to inhibit B cell proliferation as efficiently in primate as it was in human.

The alternative mode of action of Mabs is depletion of the targeted cells, either through complement or Fc $\gamma \mathrm{R}$ dependent interactions 
with the constant domain of immunoglobulins or fusion proteins. The effect of the anti-CD40L MR1 has been attributed to such depletion of activated cells in mouse models of skin or islet transplantation $[47,48]$ although a non depleting aglycosylated form of MR1 was as efficient as the native form [49]. In primates, contrasting results have been obtained, the humoral response being inhibited by non-depleting antibodies while both islet and kidney transplant were rejected as in untreated recipients [50]. When analyzed in vitro, hCD40Ig demonstrated some cytotoxic properties, although 20 times less than h5C8, suggesting that the depletion might be more important than CD40/ CD40L blockade in the in vivo effect. Nevertheless, the absence of inhibition of anti-tetanic toxoid could not be explained by such differences since humoral response was inhibited by both depleting and non-depleting anti-CD40L antibodies in a cynomolgus model [50].

The role of molecular interactions of the trimeric structures formed by CD40L and CD40 has not been fully characterized, and the effects of both anti-CD40L and hCD40Ig on signaling inhibition are unknown. Different effect on a putative reverse signaling of the CD40 molecule itself cannot be excluded either.

Lastly, we would like to comment on the complexity of the model we used. The animals in this study originated from the island of Mauritius and the samples needed for AAV serotype, ABO and DR-MHC typing screening were directly shipped to the lab in France. Because of the low genetic diversity of this population [51], and the high frequency of AAV pre-immunization (ca. 85\%), about one out of ten screened animals were selected for our study. Considering the complexity to select more animals, to produce the AAV, to declassify the animal after AAV injection before transplantation and the lack of effect of the CD40Ig in vivo after transplantation, we didn't think it was ethically and scientifically necessary to pursue this study on additional animals.

In conclusion, our gene transfer model allowed a high and persistent production of hCD40Ig in primate. Despite its ability to inhibit CD40 signaling events in vitro, no effect on rejection was seen after kidney transplantation in primate, and humoral response to vaccination was also maintained. The low depleting properties of this construct compared to the anti-CD40L h5C8, and the strong activating effect in MLR might explain the inefficacy of this molecule used as monotherapy.

\section{Acknowledgment}

This study was supported by Agence de Biomedecine grants, Progreffe grant, Société Francophone de Transplantation grant and Vaincre la Mucoviscidose grants.

We thank the personnel at the Boisbonne Centre (large animal facility) in Nantes, and the Vector Core at the University Hospital of Nantes for providing the AAV1 and AAV8 vector stocks.

We thank L. Levée from the Laboratoire d'Immunologie et Immunopathologie in Caen for technical assistance in tetanus and diphtheria toxoid ELISA.

\section{References}

[1] Linsley PS, Wallace PM, Johnson J, Gibson MG, Greene JL, Ledbetter JA, et al. Immunosuppression in vivo by a soluble form of the CTLA-4 T cell activation molecule. Science 1992;257:792-5.

[2] Lenschow DJ, Zeng Y, Thistlethwaite JR, Montag A, Brady W, Gibson MG, et al. Long-term survival of xenogeneic pancreatic islet grafts induced by CTLA4lg. Science 1992;257:789-92.

[3] Adams AB, Shirasugi N, Jones TR, Durham MM, Strobert EA, Cowan S, et al. Development of a chimeric anti-CD40 monoclonal antibody that synergizes with LEA29Y to prolong islet allograft survival. J Immunol 2005;174:542-50 [Baltimore, Md: 1950].

[4] Williams MA, Trambley J, Ha J, Adams AB, Durham MM, Rees P, et al. Genetic characterization of strain differences in the ability to mediate CD40/CD28-independent rejection of skin allografts. J Immunol 2000;165:6849-57 [Baltimore, Md: 1950].

[5] Caux C, Massacrier C, Vanbervliet B, Dubois B, Van Kooten C, Durand I, et al. Activation of human dendritic cells through CD40 cross-linking. J Exp Med 1994;180: 1263-72.
[6] Shinde S, Wu Y, Guo Y, Niu Q, Xu J, Grewal IS, et al. CD40L is important for induction of, but not response to, costimulatory activity. ICAM-1 as the second costimulatory molecule rapidly up-regulated by CD40L. J Immunol 1996;157:2764-8.

[7] Banchereau J, Bazan F, Blanchard D, Briere F, Galizzi JP, van Kooten C, et al. The CD40 antigen and its ligand. Annu Rev Immunol 1994;12:881-922.

[8] Henn V, Slupsky JR, Gräfe M, Anagnostopoulos I, Förster R, Müller-Berghaus G et al. CD40 ligand on activated platelets triggers an inflammatory reaction of endothelial cells. Nature 1998;391:591-4.

[9] Karmann K, Hughes CC, Schechner J, Fanslow WC, Pober JS. CD40 on human endothelial cells: inducibility by cytokines and functional regulation of adhesion molecule expression. Proc Natl Acad Sci U S A 1995;92:4342-6.

[10] Munroe ME, Bishop GA. A costimulatory function for T cell CD40. J Immunol 2007; $178: 671-82$.

[11] Li XL, Menoret S, Le Mauff B, Angin M, Anegon I. Promises and obstacles for the blockade of CD40-CD40L interactions in allotransplantation. Transplantation 2008;86:10-5.

[12] Haanstra KG, Ringers J, Sick EA, Ramdien-Murli S, Kuhn EM, Boon L, et al. Prevention of kidney allograft rejection using anti-CD40 and anti-CD86 in primates. Transplantation 2003;75:637-43.

[13] Hancock WW, Sayegh MH, Zheng XG, Peach R, Linsley PS, Turka LA. Costimulatory function and expression of CD40 ligand, CD80, and CD86 in vascularized murine cardiac allograft rejection. Proc Natl Acad Sci U S A 1996;93:13,967-72.

[14] Kenyon N, Chatzipetrou M, Masetti M, Ranuncoli A, Oliveira M, Wagner J, et al Long-term survival and function of intrahepatic islet allografts in rhesus monkeys treated with humanized anti-CD154. Proc Natl Acad Sci U S A 1999;96:8132-7.

[15] Kirk A, Burkly L, Batty D, Baumgartner R, Berning J, Buchanan K, et al. Treatment with humanized monoclonal antibody against CD154 prevents acute renal allograft rejection in nonhuman primates. Nat Med 1999;5:686-93.

[16] Larsen C, Elwood E, Alexander D, Ritcjie S, Hendrix R, Tucker-Bureden C, et al. Long-term acceptance of skin and cardiac allografts after blocking CD40 and CD28 pathways. Nature 1996;381:434-8.

[17] Pearson TC, Trambley J, Odom K, Anderson DC, Cowan S, Bray R, et al. Anti-CD40 therapy extends renal allograft survival in rhesus macaques. Transplantation 2002;74:933-40.

[18] Markees TG, Phillips NE, Gordon EJ, Noelle RJ, Shultz LD, Mordes JP, et al. Long-term survival of skin allografts induced by donor splenocytes and anti-CD154 antibody in thymectomized mice requires CD4 (+) T cells, interferon-gamma, and CTLA4. J Clin Invest 1998; 101:2446-55.

[19] Preston EH, Xu H, Dhanireddy KK, Pearl JP, Leopardi FV, Starost MF, et al. IDEC-131 (anti-CD154), sirolimus and donor-specific transfusion facilitate operational tolerance in non-human primates. Am J Transplant 2005;5:1032-41.

[20] Kawai T, Andrews D, Colvin RB, Sachs DH, Cosimi AB. Thromboembolic complications after treatment with monoclonal antibody against CD40 ligand. Nat Med 2000;6:114.

[21] Guillot C, Guillonneau C, Mathieu P, Gerdes CA, Menoret S, Braudeau C, et al Prolonged blockade of CD40-CD40 ligand interactions by gene transfer of CD40Ig results in long-term heart allograft survival and donor-specific hyporesponsiveness, but does not prevent chronic rejection. J Immunol 2002;168:1600-9.

[22] Guillonneau C, Hill M, Hubert F-X, Chiffoleau E, HervÇ C, Li X-L, et al. CD40Ig treatment results in allograft acceptance mediated by CD8CD45RC T cells, IFN-gamma, and indoleamine 2,3-dioxygenase. J Clin Invest 2007;117:1096-106.

[23] Toromanoff A, Cherel Y, Guilbaud M, Penaud-Budloo M, Snyder RO, Haskins ME, et al. Safety and efficacy of regional intravenous (r.i.) versus intramuscular (i.m.) delivery of rAAV1 and rAAV8 to nonhuman primate skeletal muscle. Mol Ther 2008;16: 1291-9.

[24] Toromanoff A, Adjali O, Larcher T, Hill M, Guigand L, Chenuaud P, et al. Lack of immunotoxicity after regional intravenous (RI) delivery of rAAV to nonhuman primate skeletal muscle. Mol Ther 2010;18:151-60.

[25] Poirier N, Maillet F, Barussaud ML, Renaudin K, Ashton-Chess J, Minault D, et al. Acute humoral rejection of renal transplants in alloimmunized pigs. J Surg Res 2007;139:261-8.

[26] Blancher A, Tisseyre P, Dutaur M, Apoil PA, Maurer C, Quesniaux V, et al. Study of Cynomolgus monkey (Macaca fascicularis) MhcDRB (Mafa-DRB) polymorphism in two populations. Immunogenetics 2006;58:269-82.

[27] Tillou X, Poirier N, Le Bas-Bernardet S, Hervouet J, Minault D, Renaudin K, et al. Recombinant human C1-inhibitor prevents acute antibody-mediated rejection in alloimmunized baboons. Kidney Int 2010;78:152-9.

[28] Clark EA, Ledbetter JA. Activation of human B cells mediated through two distinct cell surface differentiation antigens, Bp35 and Bp50. Proc Natl Acad Sci U S A 1986;83:4494-8.

[29] Nomura M, Yamashita K, Murakami M, Takehara M, Echizenya H, Sunahara M, et al. Induction of donor-specific tolerance by adenovirus-mediated CD40Ig gene therapy in rat liver transplantation. Transplantation 2002;73:1403-10.

[30] Kirk AD, Harlan DM, Armstrong NN, Davis TA, Dong Y, Gray GS, et al. CTLA4-Ig and anti-CD40 ligand prevent renal allograft rejection in primates. Proc Natl Acad Sci U S A 1997;94:8789-94.

[31] Montgomery SP, Xu H, Tadaki DK, Celniker A, Burkly LC, Berning JD, et al. Combination induction therapy with monoclonal antibodies specific for CD80, CD86, and CD154 in nonhuman primate renal transplantation. Transplantation 2002;74:1365-9.

[32] Kanmaz T, Fechner Jr JJ, Torrealba J, Kim HT, Dong Y, Oberley TD, et al. Monotherapy with the novel human anti-CD154 monoclonal antibody ABI793 in rhesus monkey renal transplantation model. Transplantation 2004;77:914-20.

[33] Schuler W, Bigaud M, Brinkmann V, Di Padova F, Geisse S, Gram H, et al. Efficacy and safety of ABI793, a novel human anti-human CD154 monoclonal antibody, in cynomolgus monkey renal allotransplantation. Transplantation 2004;77: 717-26. 
[34] Imai A, Suzuki T, Sugitani A, Itoh T, Ueki S, Aoyagi T, et al. A novel fully human anti-CD40 monoclonal antibody, 4D11, for kidney transplantation in cynomolgus monkeys. Transplantation 2007;84:1020-8.

[35] Azimzadeh AM, Pfeiffer S, Wu G, Schroder C, Zorn III GL, Kelishadi SS, et al. Alloimmunity in primate heart recipients with CD154 blockade: evidence for alternative costimulation mechanisms. Transplantation 2006;81:255-64.

[36] Greenlaw RE, Gardner NJ, Farrar CA, Shariff H, Sacks SH, Yagita H, et al. An antibody combination that targets activated $\mathrm{T}$ cells extends graft survival in sensitized recipients. Am J Transplant 2008;8:2272-82.

[37] Whitmire JK, Flavell RA, Grewal IS, Larsen CP, Pearson TC, Ahmed R. CD40-CD40 ligand costimulation is required for generating antiviral CD4 T cell responses but is dispensable for CD8 T cell responses. J Immunol 1999;163:3194-201.

[38] Mintern JD, Davey GM, Belz GT, Carbone FR, Heath WR. Cutting edge: precursor frequency affects the helper dependence of cytotoxic T cells. J Immunol 2002;168: 977-80.

[39] Ford ML, Koehn BH, Wagener ME, Jiang W, Gangappa S, Pearson TC, et al. Antigen-specific precursor frequency impacts $\mathrm{T}$ cell proliferation, differentiation, and requirement for costimulation. J Exp Med 2007;204:299-309.

[40] Welsh RM, Markees TG, Woda BA, Daniels KA, Brehm MA, Mordes JP, et al. Virus-induced abrogation of transplantation tolerance induced by donor-specific transfusion and anti-CD154 antibody. J Virol 2000;74:2210-8.

[41] Valujskikh A, Pantenburg B, Heeger PS. Primed allospecific T cells prevent the effects of costimulatory blockade on prolonged cardiac allograft survival in mice. Am J Transplant 2002;2:501-9.

[42] Adams AB, Williams MA, Jones TR, Shirasugi N, Durham MM, Kaech SM, et al. Heterologous immunity provides a potent barrier to transplantation tolerance. J Clin Invest 2003;111:1887-95.
[43] Arpinati M, Chirumbolo G, Rondelli D. Enhancement of T cell activation by immobilized hu5C8 (anti-CD40L) monoclonal antibody. Eur J Haematol 2008;80:322-30.

[44] Blair PJ, Riley JL, Harlan DM, Abe R, Tadaki DK, Hoffmann SC, et al. CD40 ligand (CD154) triggers a short-term CD4 $(+) \mathrm{T}$ cell activation response that results in secretion of immunomodulatory cytokines and apoptosis. J Exp Med 2000;191: 651-60.

[45] Lane P, Gerhard W, Hubele S, Lanzavecchia A, McConnell F. Expression and functional properties of mouse B7/BB1 using a fusion protein between mouse CTLA4 and human gamma 1. Immunology 1993;80:56-61.

[46] Ronchese F, Hausmann B, Hubele S, Lane P. Mice transgenic for a soluble form of murine CTLA-4 show enhanced expansion of antigen-specific CD4 + T cells and defective antibody production in vivo. J Exp Med 1994;179:809-17.

[47] Monk NJ, Hargreaves REG, Marsh JE, Farrar CA, Sacks SH, Millrain M, et al. Fc-dependent depletion of activated $\mathrm{T}$ cells occurs through CD40L-specific antibody rather than costimulation blockade. Nat Med 2003;9:1275-80.

[48] Sanchez-Fueyo A, Domenig C, Strom TB, Zheng XX. The complement dependent cytotoxicity (CDC) immune effector mechanism contributes to anti-CD154 induced immunosuppression. Transplantation 2002;74:898-900.

[49] Daley SR, Cobbold SP, Waldmann H. Fc-disabled anti-mouse CD40L antibodies retain efficacy in promoting transplantation tolerance. Am J Transplant 2008;8:2265-71.

[50] Ferrant JL, Benjamin CD, Cutler AH, Kalled SL, Hsu YM, Garber EA, et al. The contribution of Fc effector mechanisms in the efficacy of anti-CD154 immunotherapy depends on the nature of the immune challenge. Int Immunol 2004;16:1583-94.

[51] Kawamoto Y, Kawamoto S, Matsubayashi K, Nozawa K, Watanabe T, Stanley MA, et al. Genetic diversity of longtail macaques (Macaca fascicularis) on the island of Mauritius: an assessment of nuclear and mitochondrial DNA polymorphisms. J Med Primatol 2008;37:45-54. 